\title{
Oxidized cellulose as hemostatic agent to prevent bleeding after high-risk endo- scopic resection of rectal laterally spreading tumor overlying hemorrhoids
}

A 58-year-old man with a history of a hypertension, coronary heart disease, and diabetes mellitus type II was referred for evaluation of a rectal tumor. The patient had undergone coronary artery stenting and was taking dual antiplatelet therapy. On colonoscopy he was found to have a laterally spreading tumor, granular type. The polypoid lesion extended from the anal verge, continued on top of internal hemorrhoids, and extended proximally $5 \mathrm{~cm}$ into the rectum, covering about two-thirds of the rectal circumference. The patient preferred endoscopic resection to a transrectal surgery procedure.

The endoscopic resection was carried out using a gastroscope and with an endoscopic submucosal dissection-endoscopic mucosal resection (ESD-EMR) hybrid technique. Post-resection inspection revealed a complete resection (endoscopic R0), several small vessels, and exposed haemorrhoids (> Fig. 1). Prophylactic hemostasis was then achieved by applying oxidized regenerated cellulose. The oxidized cellulose was cut into $20 \times 20 \mathrm{~mm}$ pieces, grasped with a clip, which had been previously advanced through the scope and then pushed through an overtube onto the resection site. The cellulose was attached through clipping proximally ( $\triangleright$ Video 1$)$. The patient had an uneventful recovery without any rectal bleeding.

Oxidized cellulose can be considered to be a "topical" hemostatic agent, similar to Hemospray (Cook Medical, WinstonSalem, North Carolina, USA) [1]. The mechanism of action of cellulose is still unclear, but data show that it activates platelets and provides mechanical hemostasis by dehydrating or through “sponge-like' mechanisms [2, 3]. Indeed, oxidized cellulose is generally used in heavy bleeding, including in liver surgery, because of its high absorptive capacity due to its dense fibrous composition. Oxidized cellulose can absorb up to seven times its physiological weight, and has

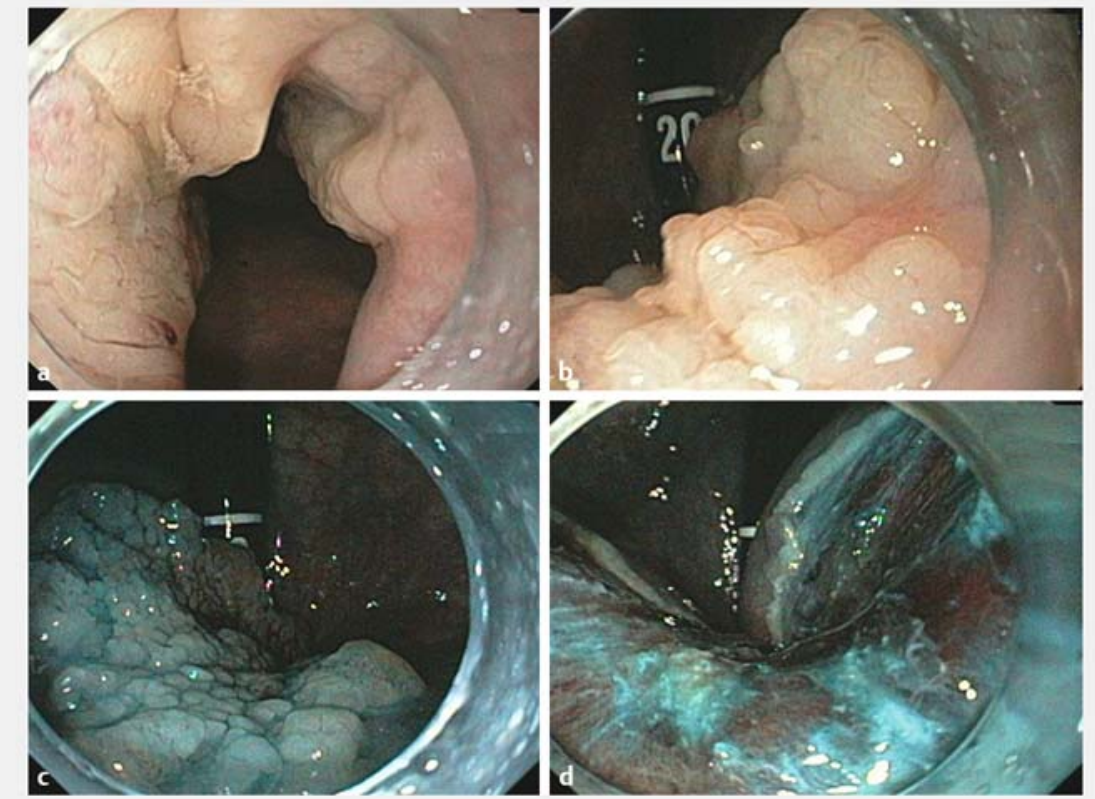

Fig. 1 High-risk resection of laterally spreading tumor. a Large laterally spreading tumor (LST) of the rectum, starting at the anal verge at the linea dentate. b Retroflexed view of the LST. c Chromoendoscopy with indigo carmine to better define and delineate the lesion in preparation for resection. A transparent cap was attached to the scope to assist during endoscopic dissection and resection. $\mathbf{d}$ Post-resection inspection revealed a complete resection (endoscopic R0), several small vessels, and exposed hemorrhoids.

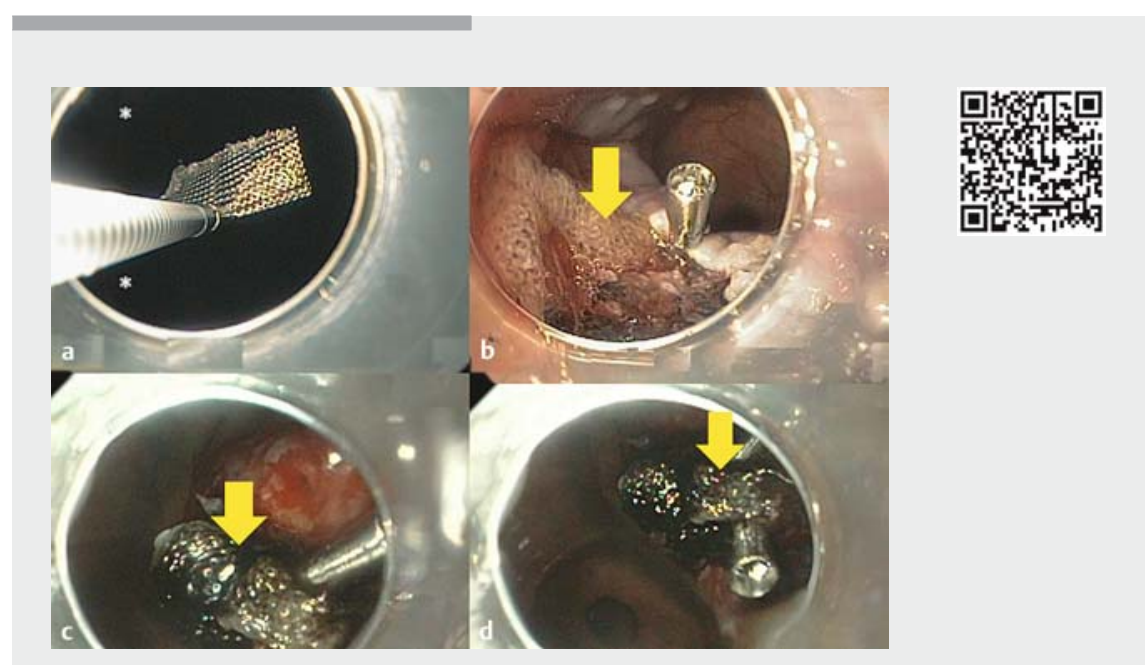

$\checkmark$ Video 1 Prophylactic hemostasis was achieved by applying oxidized regenerated cellulose. The oxidized cellulose was cut into $20 \times 20 \mathrm{~mm}$ pieces, grasped with a hemoclip, which had been previously advanced through the scope (a) and then pushed through an overtube onto the resection site. The cellulose (arrows) was attached through clipping proximally $(\mathbf{b}-\mathbf{d})$. 
the advantage of being biodegradable, biocompatible, reabsorbed by hydrolysis, and without immunological risk [3-5].

Endoscopy_UCTN_Code_TTT_1AQ_2AZ

\section{Competing interests}

Klaus Mönkemüller is a speaker and consultant for Cook Medical, USA.

The authors

Seiichiro Abe ${ }^{1}$, Alvaro Martinez-Alcalá2 K. Kyanam Kabir Baig ${ }^{3}$, Yutaka Saito ${ }^{1}$, Klaus Mönkemüller ${ }^{4}$

1 Division of Gastrointestinal Endoscopy, National Cancer Center, Tokyo, Japan

2 Department of Gastroenterology, Hospital Universitario Infanta Leonor, Madrid, Spain

3 Basil Hirschowitz Endoscopic Center of Excellence, University of Alabama, Birmingham, USA

4 Department of Visceral Surgery Helios Klinikum, Kronach, Germany
Corresponding author

Klaus Mönkemüller, MD, PhD, FASGE

Department of Surgery, Division of Endoscopy, Helios Frankenwaldklinik, Friesenerstr. 44, Kronach, Germany moenkemueller@yahoo.com

\section{References}

[1] Holster IL, Kuipers EJ, Tjwa ET. Hemospray in the treatment of upper gastrointestinal hemorrhage in patients on antithrombotic therapy. Endoscopy 2013; 45: 63-71

[2] Spangler D, Rothenburger S, Nguyen K et al. In vitro antimicrobial activity of oxidized regenerated cellulose against antibiotic-resistant microorganisms. Surg Infect 2003; 4: $255-262$

[3] Spotnitz WD. Active and mechanical hemostatic agents. Surgery 2007; 142: S34 - S38

[4] Samudrala S. Topical hemostatic agents in surgery: a surgeon's perspective. AORN J 2008; 88: S2 - S11

[5] Velázquez-Aviña J, Mönkemüller K, Sakai P et al. Hemostatic effect of oxidized regenerated cellulose in an experimental gastric mucosal resection model. Endoscopy 2014; 46: $878-882$

\section{Bibliography}

DOI https://doi.org/10.1055/s-0043-125357

Published online: 2.2.2018

Endoscopy 2018; 50: E95-E96

(c) Georg Thieme Verlag KG

Stuttgart · New York

ISSN 0013-726X

\section{ENDOSCOPY E-VIDEOS \\ https://eref.thieme.de/e-videos}

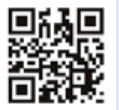

Endoscopy E-Videos is a free access online section, reporting on interesting cases and new

techniques in gastroenterological endoscopy. All papers include a high quality video and all contributions are freely accessible online.

This section has its own submission website at https://mc.manuscriptcentral.com/e-videos 